\title{
Nano Grid Based Smart Homes With Electricity Production \& Trading Facility
}

\author{
Shiwani Goyal ${ }^{1}$, Mrs. Shimi S.L ${ }^{2}$ \\ M.E Scholar (Instrumentation and Control), NITTTR, Chandigarh ${ }^{1}$ \\ Assistant Professor, Electrical Engineering Department, NITTTR, Chandigarh ${ }^{2}$
}

\begin{abstract}
When building houses, office structures or modern plants, financial specialists are concerned about the development costs, as well as more regularly at the future expenses of utilization. They can put more in the first place, to make sure that before long the venture will pay itself back and begin bringing benefits. Considering such speculators decentralized control, change and oversight frameworks were made - called smart home frameworks. This is the idea of smart home. Nano grids are small micro grids, typically serving a single building or a single load. Navigant Research has developed its own definition of a nano grid as being $100 \mathrm{~kW}$ for grid-tied systems and $5 \mathrm{KW}$ for remote systems not interconnected with a utility grid. Nano grids mimic the innovation that is rising up from the bottom of the pyramid and capturing the imagination of growing numbers of technology vendors and investment capital, particularly in the smart building and smart transportation spaces, says Navigant. In other ways, nano grids are more conventional than micro grids since they do not directly challenge utilities in the same way. Nano grids are restricted to a single building or a single load, and therefore do not bump up against regulations prohibiting the transfer or sharing of power across a public right-of-way. From a technology point of view, perhaps the most radical idea behind nano grids is a clear preference for direct current (DC) solutions, whether these systems are connected to the grid or operate as standalone systems, according to Navigant.
\end{abstract}

Keywords: Smart grid, Nano grid, Smart Homes, MHTG-micro hydro turbine generator set.

\section{INTRODUCTION}

In this postulation, specialist proposes and discusses splendid homes that not simply eat up power but rather are fit for creating it. Making it one walk facilitate, agent see these homes as splendid and adaptable as they settle on selfdecisions to manage their energy stockpiling. In addition, they can associate with the grid to trade control in a manner of speaking that benefits them the most. The idea is to supply such lights with clean electricity and isolated from the network. To answer this problem, one solution consists on the association of photovoltaic (PV) panel and battery. Battery can store energy from PV panel during the day and give it back during the night [1]. Optimization of standalone hybrid renewable energy storage (HRES) can be done for street light application also by combining optimization process in supply side of street light. Optimization is aimed to get better configuration with minimum loss and minimum cost [2]. The rapidly increasing use of electricity for street lighting at the present time is due not so much to the efficiency of these lamps but to the fact that light can be distributed from them in any required direction by simple optical means. Hence the most notable feature of modern street lighting is the large number of electric lamps fitted with reflectors or glassware designed specially for distributing the total light most efficiently [3]. Similar, study is done on street lighting of Manchester. The detailed information relates to the lighting of Portland street Manchester, by means of flame arc lamps and the scheme adopted can only be judged by comparisons, data relating to earlier systems of arc lighting and contemporary systems of high-pressure gas lighting [4]. A designing of automatic control circuit of LED street lamp is made. The circuit is supplied with solar cell and stored electric energy with battery which can be supplied by pv modules [5]. The performance of $21 \mathrm{PV}$-powered low pressure sodium lighting systems on a multi-use pathway has been observed Specific areas for evaluation include the constant voltage and on/off PV charge controllers, flooded deep-cycle lead-antimony and valve regulated lead-acid (VRLA) gel batteries, low pressure sodium ballasts and lights and vandal resistant PV modules [6]. Smart Grid Vision for India is to transform the Indian power sector into a secure, adaptive, sustainable, and digitally enabled ecosystem that provides reliable and quality energy for all with active participation of stakeholders. Smart Grid pilot projects are planned to be executed in power distribution sector in India [7].In fact, a green building energy system can be installed that consists of renewable energy, energy storage, and energy management. The architecture of green building energy system and a simulation model can be made that allows for the study of advanced control strategies for the green building energy system [8]. The current electrical power systems are encountering a transform from the customary matrix to the propelled grid named the Smart Grid. The new and propelled grid offers greater adaptability and dependability to clients and for the makers of electrical energy. Smart 


\section{IJIREEICE \\ International Journal of Innovative Research in Electrical, Electronics, Instrumentation and Control Engineering \\ ISO 3297:2007 Certified \\ Vol. 5, Issue 5, May 2017}

Grid permits ongoing administration of vitality free market activity subsequently making the client one of the basic parts in the entire power dispersion framework.

\section{SMART GRID}

The concept of the Smart Grid (SG), also called smart power grid, smart electrical grid, intelligrid, intragrid, intergrid, intelligent grid or future grid is no different from the traditional term but with certain enhancements that contain the integration of information systems into the electrical energy distribution grid. In general, the traditional power grids are used to transfer power from a few and centralized power generation facilities to a large number of potential customers over a vast geographical area. The smart grid allows real time tracking and management of energy supply and demand thereby making the customer one of the essential roles in the whole power distribution system.

\section{TOOLS AND SOFTWARES USED}

\section{LabVIEW}

LabVIEW (short for Laboratory Virtual Instrument Engineering Workbench) is a system-design platform and development environment for a visual programming language from National Instruments.

LabVIEW is an exceptionally beneficial working environment for making custom applications that cooperate with genuine information or signs in fields, for example, science and designing. The net after effect of utilizing an apparatus, for example, LabVIEW is that higher quality ventures can be finished in less time with fewer individuals involved.

\section{PROJECT OBJECTIVE}

Following are the expected outcome of this study

- Software which will give direction regarding the power generation, storage it's trading and its cost and placement.

- Software will give the details of possible hardware required when it will be required to implement in any building.

- Small prototype will be developed for calculating the production and other related data. Each house can generate electrical energy and can utilize it there itself and in case of extra energy generated, it can be transferred and sold in the global market.

- Smart grid and nano grids can be used to sell the energy developed at nano level.

\section{DESCRIPTION OF THE SOFTWARE}

The software is divided into five parts:

\section{(i) Hydro Power System}

In this section hydro generation is modeled. All the hydro-electric generation depends on falling water. A small-scale hydro system usually consists of an enclosed wheel or turbine, which is made to spin by jets of high velocity water. The measured output of turbine is given to generator. Battery is used to store power in terms of non-availability of power from hybrid system.

(ii) Hydro and Solar Power Income

This section gives the output i.e. hydro and solar power income in rupees per annum. The Fig. 2 shows the block diagram for the corresponding hydro and solar power income. The income calculated is given as,

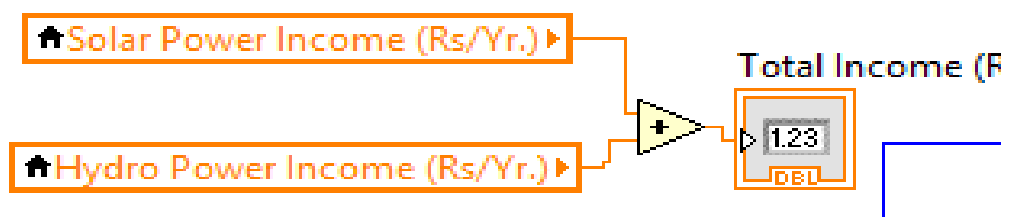

Fig. 1 Block Diagram for Corresponding Solar and Hydro Power Income

\section{(v) Solar Power System}

This section handles the power generation due to solar energy. The inputs of solar power system are solar light intensity, photovoltaic cell voltage, voltage after controller, solar voltage after regulator. Solar cells are the building blocks of photovoltaic modules known as solar panels. They are used as a photo detector for detecting light or other electromagnetic radiation or measuring light intensity. 


\section{FUZZY LOGIC DEVELOPED FOR HYBRID SYSTEM}

- Fuzzy is a system of variables that are associated with fuzzy logic. Fuzzy logic has been employed to handle the concept of partial truth, where the truth value may range between completely true and completely false. Fuzzy system consists of three main parts.

- Linguistic variables

- Membership functions

- Rules

The first fuzzy system design is for hydro generator voltage fs. The membership function for input variable (generator voltage) varies from 0 to 1 representing zero, low, medium and high values of voltage. The Fig. 2 shows the surface graph for hydro generator voltage.

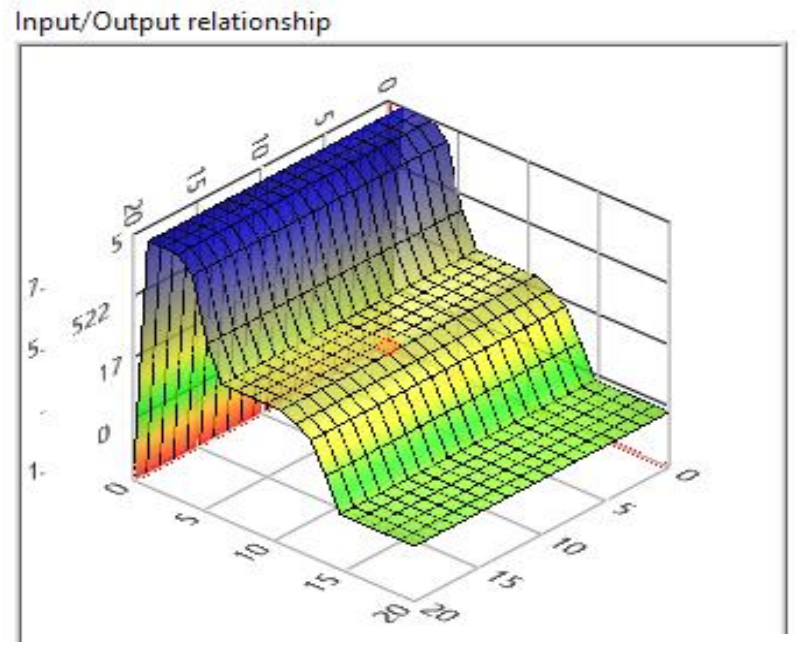

Number of input 1 sample Number of output 2 samples

$$
20 \div
$$$$
20 \div
$$

Fig. 2 Surface Graph of Hydro Generator Voltage

The other two fuzzy system developed is solar and inverter voltage $\mathrm{f}_{\mathrm{s}}$. A solar inverter or pv converter converts the variable direct current output of a photovoltaic solar panel into utility frequency alternating current that can be fed into commercial electrical grid or can be used by local network. The Fig.3 shows the variation of output voltage of hybrid system.

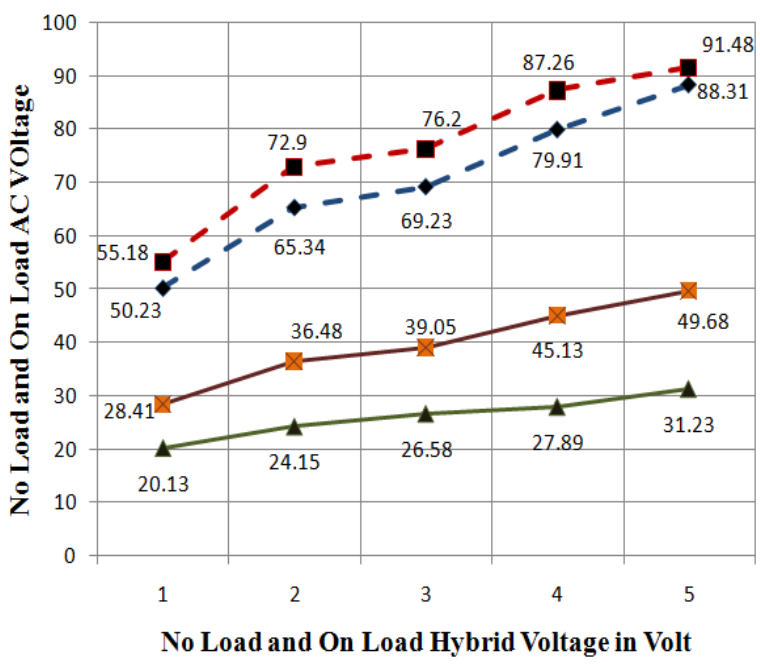

Number of input 1 sample

Number of output 2 samples

Fig.7 Variation of Theoretical and Practical values of Hybrid Voltage 


\section{IJIREEICE \\ Vol. 5, Issue 5, May 2017}

The software for design and analysis of smart grid model using intelligent hybrid nano grid is developed and tested with real time data. A small prototype of the hybrid system is implemented and variation of output ac voltage from its theoretical value is calculated in terms of error which is $8.21 \%$.

\section{CONCLUSION}

There is extreme power emergency in India. The fundamental wellspring of energy which is accessible wherever is sun based energy and water energy. Presently a days the sun oriented energy is utilized broadly all over. However this water energy at nano lattice level is not used so effectively. The agent has given worry in the use of sun powered and hydro and came to a conclusion that it is exceptionally beneficial and it can expel the deficiency of electrical energy issue upto some higher degree. The proposition report will be to a great degree valuable for electrical and power engineers.

\section{REFERENCES}

[1] Mohamed Becherif, Damien Paire and Abdellatif Miraout, "Energy Management of Solar Panel and Battery System with Passive Control", ICCEP '07, IEEE International Conference Clean Electrical Power, France, pp:14-19, March, 2007.

[2] Jeremy Lagorse, Stefan Giurgea, Damien Paire and Maurizio Cirrincione, "Optimal Design Analysis of a Stand-Alone Photovoltaic Hybrid System”, IEEE Industry Applications Society Annual Meeting, France, pp:1-7 , Jan, 2008.

[3] Haydn T. Harrison, "Street Lighting By Modern Electric Lamps", Electrical Engineers, Journal of the Institution, pp: 24-46, 24 ${ }^{\text {th }}$ Nov., 1911.

[4] S. L. Pearce, "Recent Developments In The Street Lighting Of Manchester", Electrical Engineers, Journal of the Institution, pp: 596-634, 6 March, 1913.

[5] Wang Yongqing, "Design of Solar LED Street Lamp Automatic Control Circuit", IEEE International Conference on Energy and Environment Technology, China, pp: 90-93, august, 2009.

[6] Steve R. Harrington and Thomas D. Hund, "Photovoltaic Lighting System Performance", IEEE Twenty Fifth Photovoltaic Specialists Conference, Washington, Vol.2,pp.1307-1310, 13-17 May, 1996.

[7] Alekhya Datta, P, and M. Gujar "Accelerated Deployment of Smart Grid Technologies In India -Present Scenario, Challenges And Way Forward”, IEEE International Conference on IGST, New Delhi, Vol.92, pp: 1-5, 19-22 Feb, 2014.

[8] Zhenhua Jiang, "Design, Modeling and Simulation of a Green Building Energy System", IEEE Journal, Power and Energy Society General Meeting, Calgary, Vol.26, No. 11, pp. 1-7, September, 2009.

[9] Rocky, T.H., "Nano Solar Grid (NSG): A Solution for Rural Market Power Crisis" IEEE International Conference on ICGET, Dhaka, Vol.2, pp. $14-17,5-6$ September, 2014.

[10] Shwehdi, M.H., "Proposed Smart DC Nano-Grid for Green Buildings - A Reflective View" IEEE International Conference ICRERA, Milwaukee, WI, Vol.2, pp. 765 - 769, 19-22 October, 2014.

[11] Awad, Mahmoud, Alhosani, Mohamed Ali ; Kady, Rani, "An Economical Analysis of Residential Hybrid Solar-Wind Power Generators in Abu Dhabi”, IEEE International Conference on IEOM, Dubai, United Arab Emirates, pp. 1 - 7, 3-5 March 2015.

[12] Ravinder Kumar Kharba, S.L. Shimi, S. Chatterji, Md. Fahim Ansar, "Modeling of Solar PV Module and Maximum Power Point Tracking using ANFIS” Elsevier Renewable and Sustainable Energy Reviews, Vol. 33, pp.602-612,18 February 2014. 